\title{
CONVERSION OF THE ANGLO-AUSTRALIAN OBSERVATORY LIBRARY CARD CATALOGUE USING PC SOFTWARE
}

\author{
Robyn M. Shobbrook \\ Anglo-Australian Observatory
}

A commercial software package has been used on a personal computer for the conversion of the Anglo-Australian Observatory card library catalogue. The software is sophisticated but has proven to be extremely flexible and easy to use for any library management task. The software is available at three levels; the AAO has the top level which allows for eight different databases on the one system. Each record may contain up to nine pages or screens of information and there is also a thesaurus facility. Although a multi-user system was preferred the cost of the software was out of the question. The flow-chart (Fig 1.) describes how a multi-user system was created from software designed for a single-user PC. The main files have been down-loaded in accession number order onto the VAX 11/780 minicomputer and these may be accessed on any terminal either at the laboratory headquarters at Epping in Sydney or at the telescope site at Coonabarabran $500 \mathrm{kms}$ north-west of Sydney. The 'read-only' files can be searched using the VAX edit commands and a VAX sort facility is available for a listing of selected items if required. As a substitute measure this is proving to be most useful. Later when the files are too large and searching becomes slow it may be possible to purchase additional copies of the commercial PC software which allows more sophisticated search procedures.

In this way the high cost of multi-user software packages has been avoided but users have not been deprived of access to information on the library resources. This is particularly important at the remote telescope site. A further possibility is to supply copies of the AAO catalogue to other institutions either as a connect online facility or on magnetic tape. 


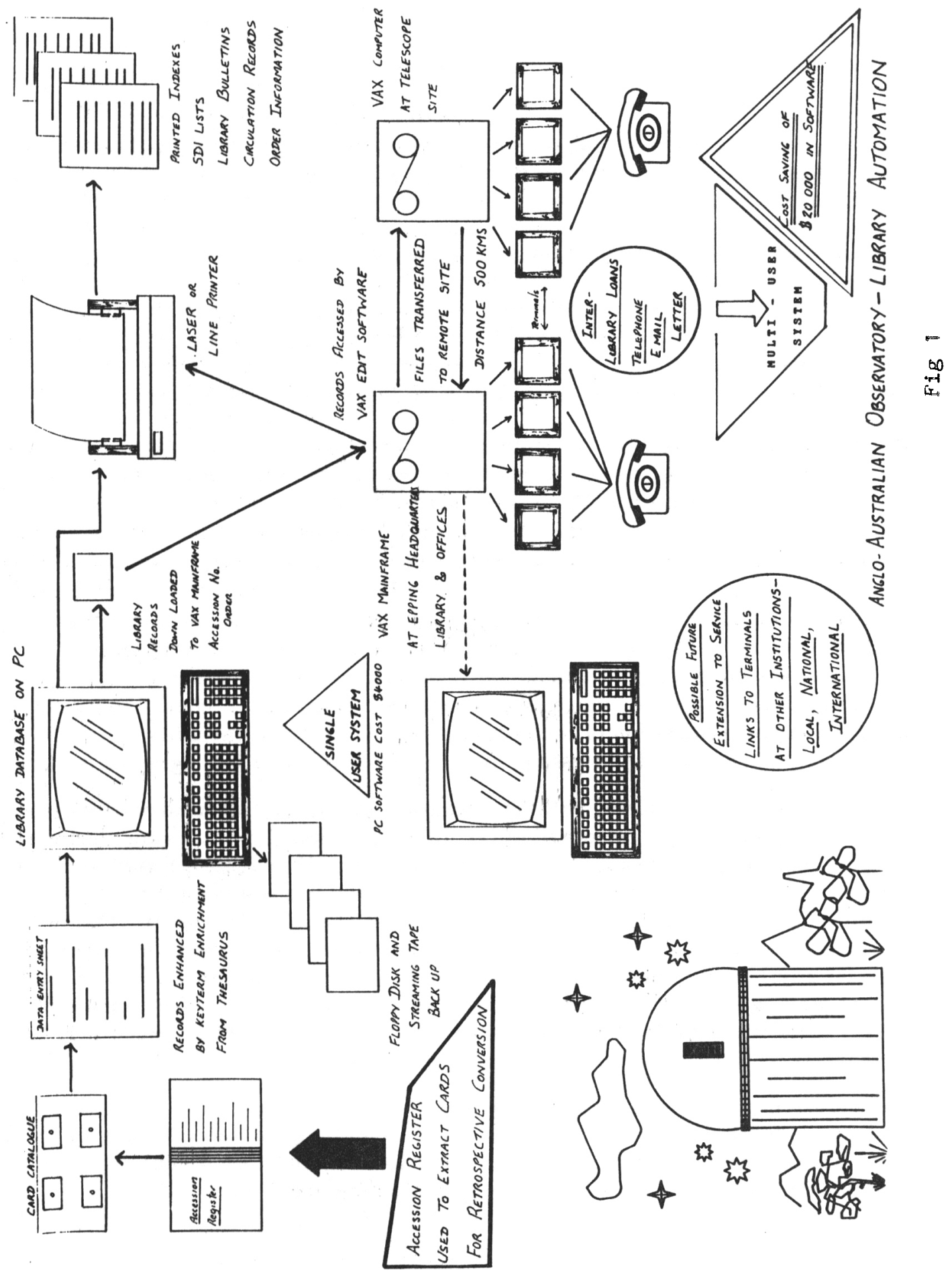

